Original Article

\title{
Effects of chewing gum on driving performance as evaluated by the STISIM driving simulator
}

\author{
InGYu Yoo ${ }^{1)}$, Eun-Joo Kim${ }^{1)^{*}}$, Joo-Hyun LeE ${ }^{2)}$ \\ 1) Department of Occupational Therapy, College of Medical Sciences, Jeonju University: Hyoja-dong \\ 3-ga, Wansan-gu, Jeonju-si, Jeollabuk-do 560-759, Republic of Korea \\ 2) Department of Occupational Therapy, College of Health Science, Yonsei University, Republic of \\ Korea
}

\begin{abstract}
Purpose] The purpose of this study was to determine the effects of chewing gum on driving performance in a driving simulator. [Subjects] In total, 26 young licensed drivers participated. [Methods] The driving scenario was typical of an urban environment: a single-carriageway, two-way road consisting of a mix of curved and straight sections, with considerable levels of traffic, pedestrians, and parked cars. Mean distance driven above the speed limit, lane position, mean distance driven across the center line, and mean distance driven off the road were used as estimates of brake, accelerator, and steering control. The results were compared with those of a nonchewing gum control condition. [Results] The driving performance while chewing gum was significantly better: the mean distance driven above the speed limit was $26.61 \%$ shorter, and the mean distance driven off the road was $31.99 \%$ shorter. Lane position and mean distance driven across the center line did not differ significantly between the two conditions. [Conclusion] Chewing gum appears to enhance driving performance during a sustained attention driving task.

Key words: Attention, Driver, Performance
\end{abstract}

(This article was submitted Jan. 21, 2015, and was accepted Feb. 26, 2015)

\section{INTRODUCTION}

Generally, driving requires a high level of arousal for awareness and responsiveness ${ }^{1}$. However, cognitive function tends to decline with age, which can affect the ability to drive safely. The accident rate per mile driven among drivers over the age of 65 has been found to be higher than that among middle-aged drivers, and when injured in a collision, these older drivers are also more likely to die or to sustain serious injuries ${ }^{2}$. Cognitive psychologists have demonstrated that the anterior attention system plays a major role in higher-level executive control of attention during more complex cognitive tasks, such as problem-solving and decision-making, especially when multi-tasking ${ }^{3}$. Interestingly, chewing gum has recently been reported to enhance cognitive performance ${ }^{4)}$. For example, Stephens and Tunney ${ }^{5)}$ provided evidence that chewing gum increases scores in immediate, delayed recall, and working memory tests. Similarly, Johnson and Miles ${ }^{6}$ ) confirmed that chewing gum during learning and/or recall improves subsequent memory. The cognitive processes improved by chewing have been systematically investigated and include memory, attention,

*Corresponding author. Eun-Joo Kim (E-mail: kimot@jj.ac. $\mathrm{kr})$

(C2015 The Society of Physical Therapy Science. Published by IPEC Inc. This is an open-access article distributed under the terms of the Creative Commons Attribution Non-Commercial No Derivatives (by-ncnd) License $<$ http://creativecommons.org/licenses/by-nc-nd/3.0/> . and executive function ${ }^{5)}$. Specifically, gum-chewing during cognitive testing has been found to improve verbal working memory and immediate episodic long-term memory, sustained attention and language-based attention. The results for gum-chewing's effects on word-association executive function are conflicting ${ }^{7}$. On the basis of these previous reports, we hypothesized that chewing gum would improve sustained attention and executive function. Thus, the purpose of this study was to determine the effects of chewing gum on driving performance. To assess this, subjects performed simulated driving tasks while chewing gum and then without.

\section{SUBJECTS AND METHODS}

The subjects comprised 26 young drivers (10 females) who held valid driving licenses (mean driving distance, $87,200 \pm 31,134 \mathrm{~km} /$ year; possession of driver's license, $3.40 \pm 2.20$ years). All subjects were informed of the purpose and methods of the study prior to participation and provided their informed consent, following the ethical principles of the Declaration of Helsinki. Participant information was obtained by interview and self-report. Exclusion criteria were (i) inability to chew gum for a period of approximately $30 \mathrm{~min}$, (ii) age younger than 18 or older than 40 years, (iii) consumption of more than 40 units of alcohol per week, (iv) smoking more than 10 cigarettes per day, (v) currently taking medication, (vi) currently experiencing medical problems (including dental problems) or serious medical conditions, and (vii) allergies to gum ${ }^{6}$. A STISIM Drive M400 
driving simulator (System Technology Inc., Hawthorne, CA, USA) was used to provide subjects with various driving environments and to estimate their driving performance. The simulator consists of a car unit with adjustable car seats with a dashboard, a steering wheel, turn signals, and brake and gas pedals, and provides a $135^{\circ}$ field of view of a simulated environment. Realistic roadway scenery is projected on a wide computer monitor, placed in front of the center of the steering wheel. Speed and gear numbers are displayed on the screen. Auditory feedback is provided through speakers and includes the sound of the engine, braking, speeding around curves, wheels, and driving off the road. Before assessment in the simulator, subjects practiced for $5 \mathrm{~min}$. If a participant demonstrated comfortable performance in the driving trial, he or she was allowed to participate in the test trials. A 3-day break was provided after each trial: not chewing gum and chewing spearmint sugar-free gum. The order of the conditions was randomized. In the chewing-gum condition, participants chewed gum at their normal speed $(1 \mathrm{~Hz})$ during driving. In the control condition, no gum was provided, and no chewing took place. The $\sim 30$-min driving scenario consisted of a two-lane highway in each direction, with a lane width of $3.5 \mathrm{~m}$. Subjects were instructed to drive in a steady lateral position in the right (slower) traffic lane, following a lead vehicle, while maintaining a steady speed of $80 \mathrm{~km} / \mathrm{h}$. Participants were required to maintain speed limits, comply with traffic rules, and negotiate surrounding traffic. The scenario presented a two-lane road with horizontal curves. Mean distance driven above the speed limit, lane position, mean distance driven across the center line, and mean distance driven off the road were estimated by the simulator equipment and used as estimates of the driver's abilities of brake, accelerator, and steering control. Differences in driving performance between the no-chewing condition and the chewing gum condition and between genders were assessed using the paired t-test. The Kolmogorov-Smirnov test confirmed the data had a normal distribution; therefore, parametric statistics were used. A p value $<0.05$ was considered to indicate statistical significance in all tests.

\section{RESULTS}

While chewing gum, drivers drove significantly shorter distances at speeds exceeding the speed limit $(26.61 \%$ shorter) and off the road (31.99\% shorter) than those while not chewing $(\mathrm{p}<0.05)$. However, lane position and mean distance driven across the center line did not differ significantly ( $p>0.05$; Table 1), and there was no effect of gender in either condition.

\section{DISCUSSION}

Safe driving demands the capacity to concentrate and to divide attention over multiple sensory events, including visual and auditory modalities; it also requires high-level cognitive decisions in a rapidly changing environment ${ }^{8)}$. In other words, driving skills require the simultaneous integration of many types of information while coordinating movements ${ }^{3)}$. Simulated driving studies indicate that measures of driving behavior, such as speed, lane position, and time/distance across the center line and off the road edge, correlate with a driver's comfort with the given driving conditions. Driving is a complex task requiring appropriate responses to hazardous situations on the road, and research has shown that attention and executive function correlate with driving status. The STISIM driving simulator is widely used to examine the driving abilities of drivers with poor performance ${ }^{9)}$. This study assessed mean speed, mean distance driven above the speed limit, lane position, mean distance driven across the center line, and mean distance driven off the road edge as proxies for driving performance. Chewing gum significantly reduced the distances above the speed limit and off the road. Previous studies have indicated that chewing gum during specific tasks improves reaction times $^{10)}$ and has positive impacts on activities requiring cognitive function. Gum chewing may improve cognitive function by promoting regional cerebral blood flow and glucose delivery and by increasing the efficiency of attention and concentration ${ }^{11,12)}$. Poor performance in a task requiring divided attention is frequently observed in adults with dementia, and previous studies have shown that divided attention problems also exist in many individuals with mild cognitive impairment ${ }^{13)}$. Cognitively impaired older drivers often do not intend to restrict or stop driving in the future, and do not consider their cognitive problems to be serious; thus, gum-chewing may reduce the risk of accidents among these individuals while their impairments remain mild ${ }^{3)}$. Our conclusion is that chewing gum enhances alertness and attention while driving, because it makes drivers feel more comfortable during driving activities. Also, this study has provided further evidence that driving simulators can be used to assess responses to road hazards in a safe environment. Driving simulator recordings have previously been used to assess age-related changes in driving performance and cognition ${ }^{14)}$, and to predict potential future crashes by older drivers ${ }^{15)}$. Further research may clarify the mechanism by which chewing gum improves performance in a task, such as driving, that requires sustained attention and executive function.

Table 1. Effect of gum-chewing on driving capacity $(\mathrm{N}=26)$

\begin{tabular}{lcc}
\hline & \multicolumn{2}{c}{ Chewing gum condition (mean \pm SD) } \\
\cline { 2 - 3 } & No gum & Chewing gum \\
\hline Mean distance driven above speed limit $(\mathrm{m})$ & $609.9 \pm 190.9$ & $456.5 \pm 166.9^{*}$ \\
Lane position $(\mathrm{m})$ & $6.79 \pm 0.46$ & $6.81 \pm 0.54$ \\
Mean distance driven across center line $(\mathrm{m})$ & $59.2 \pm 34.3$ & $43.5 \pm 32.9$ \\
Mean distance driven off road $(\mathrm{m})$ & $127.0 \pm 77.5$ & $86.4 \pm 47.9^{*}$ \\
\hline
\end{tabular}




\section{REFERENCES}

1) Hu TY, Xie X, Li J: Negative or positive? The effect of emotion and mood on risky driving. Transp Res, Part F Traffic Psychol Behav, 2013, 16: 29 40. [CrossRef]

2) Carr DB, Meuser TM, Morris JC: Driving retirement: the role of the physician. CMAJ, 2006, 175: 601-602. [Medline] [CrossRef]

3) Kowalski K, Love J, Tuokko H, et al.: The influence of cognitive impairment with no dementia on driving restriction and cessation in older adults. Accid Anal Prev, 2012, 49: 308-315. [Medline] [CrossRef]

4) Tucha $\mathrm{O}$, Mecklinger L, Maier K, et al.: Chewing gum differentially affects aspects of attention in healthy subjects. Appetite, 2004, 42: 327-329. [Medline] [CrossRef]

5) Stephens R, Tunney RJ: Role of glucose in chewing gum-related facilitation of cognitive function. Appetite, 2004, 43: 211-213. [Medline] [CrossRef]

6) Johnson AJ, Miles C: Evidence against memorial facilitation and contextdependent memory effects through the chewing of gum. Appetite, 2007, 48: 394-396. [Medline] [CrossRef]

7) Onyper SV, Carr TL, Farrar JS, et al.: Cognitive advantages of chewing gum. Now you see them, now you don't. Appetite, 2011, 57: 321-328. [Medline] [CrossRef]
8) Spiers HJ, Maguire EA: Neural substrates of driving behaviour. Neuroimage, 2007, 36: 245-255. [Medline] [CrossRef]

9) Shechtman O, Classen S, Awadzi K, et al.: Comparison of driving errors between on-the-road and simulated driving assessment: a validation study. Traffic Inj Prev, 2009, 10: 379-385. [Medline] [CrossRef]

10) Smith A: Effects of chewing gum on cognitive function, mood and physiology in stressed and non-stressed volunteers. Nutr Neurosci, 2010, 13: 7-16. [Medline] [CrossRef]

11) Smith A: Effects of chewing gum on mood, learning, memory and performance of an intelligence test. Nutr Neurosci, 2009, 12: 81-88. [Medline] [CrossRef]

12) Mehta RK, Parasuraman R: Effects of mental fatigue on the development of physical fatigue: a neuroergonomic approach. Hum Factors, 2014, 56: 645-656. [Medline] [CrossRef]

13) Okonkwo OC, Griffith HR, Belue $\mathrm{K}$, et al.: Cognitive models of medical decision-making capacity in patients with mild cognitive impairment. J Int Neuropsychol Soc, 2008, 14: 297-308. [Medline] [CrossRef]

14) Shin HK, Lee HC: Characteristics of driving reaction time of elderly drivers in the brake pedal task. J Phys Ther Sci, 2012, 24: 567-570. [CrossRef]

15) Fukuda T: The influence of aging on balance function in terms of the foot electromyographic reaction time. J Phys Ther Sci, 2012, 24: 191-196. [CrossRef] 